\title{
Effect of compressive loading on first-year sea-ice permeability
}

\author{
CARL E. RENSHAW, ${ }^{1,2}$ ALEKSEY MARCHENKO, ${ }^{3}$ ERLAND M. SCHULSON, $^{2}$ \\ EVGENY KARULIN ${ }^{4}$
}

\author{
${ }^{1}$ Department of Earth Sciences, Dartmouth College, Hanover, NH, USA \\ ${ }^{2}$ Thayer School of Engineering, Dartmouth College, Hanover, NH, USA \\ ${ }^{3}$ Department of Arctic Technology, The University Centre in Svalbard, Longyearbyen, Svalbard and Jan Mayen \\ ${ }^{4}$ Krylov State Research Center, St. Petersburg, Russian Federation \\ Correspondence: Carl E. Renshaw <Carl.Renshaw@Dartmouth.edu>
}

\begin{abstract}
The permeability of sea ice can strongly affect the dissipation of wave energy into the ice pack. Sea-ice permeability is known to be impacted by the brine volume fraction and the blockage of flow pathways by the freezing of infiltrating lower salinity water. Here we investigate another process impacting sea-ice permeability, namely, inelastic deformation. We report the results of a first-of-itskind field-scale deformation experiment to investigate the impact of compressive loading on sea-ice permeability. We observed that deformation decreased permeability by four orders of magnitude or more in some locations, while elsewhere permeability was unaffected or possibly increased. We show that the observed changes in permeability are consistent with expected changes in stress state and, as a result, in the mechanisms of deformation.
\end{abstract}

KEYWORDS: ice physics, sea-ice dynamics, sea-ice modelling

\section{INTRODUCTION}

As sea-ice extent in polar regions decreases (e.g., Stroeve and others, 2012), increasing open water fetches are generating larger waves (Thomson and others, 2016), which may propagate farther into the pack ice and potentially break it up (Asplin and others, 2012; Thomson and Rogers, 2014). Failure likely occurs due to wave-induced bending of the ice cover, which induces cyclic compressional and tensional stresses in the ice. The stress amplitude of loading is proportional to the wave amplitude and therefore depends on the wave attenuation along the ray of wave propagation below the ice. Potentially destructive compressional stresses due to wave-induced bending are enhanced when wind pushes the ice perpendicular to a coastline (Tremblay and Hakakian, 2006). These processes are more likely to operate in the late summer and early fall when the ice is warm and the fetch long.

The capacity of waves to penetrate into sea ice depends on the dissipation rate of the wave energy by the ice. Field observations of wave events in the Barents Sea have shown that wave damping is stronger in solid ice and reduced significantly when the ice is broken into floes by waves (Collins and others, 2015). Marchenko and Cole (2017) found that when the saline ice permeability is $>10^{-9} \mathrm{~cm}^{2}$, corresponding to a brine volume fraction of $\sim 5 \%$ (Golden and others, 2007), wave-energy dissipation is dominated by the migration of liquid brine through the ice, highlighting the important role of ice permeability on wave-energy dissipation.

Sea-ice permeability is known to exhibit a percolation threshold at a critical brine volume fraction of $\sim 5 \%$ (Golden and others, 1998; Golden and others, 2007; Pringle and others, 2009). For a typical bulk ice salinity of $5 \mathrm{ppt}$, this fraction corresponds to a critical temperature of $\sim-5{ }^{\circ} \mathrm{C}$. Here we investigate another process that possibly impacts sea-ice permeability, namely inelastic deformation.
Cracks are common in sea ice (Marko and Thomson, 1977; Kwok, 2001; Schulson, 2004) and likely form in response to wind- or wave-driven deformation (Richter-Menge and others, 2002; Marchenko and Cole, 2017). Above a critical crack density, cracks link together to create a continuous pathway for flow (Renshaw, 1999; Renshaw and others, 2017). We recently demonstrated that in $\sim 150 \mathrm{~mm}$ cubes of fresh water columnar ice at $-10^{\circ} \mathrm{C}$ deformed uniaxially by loading across the columns at a strain rate of $10^{-5} \mathrm{~s}^{-1}$, inelastic deformation and the attendant creation of short cracks results in the formation of a connected flow pathway along the columns (i.e., the onset of percolation) at a strain of $\varepsilon=0.38 \pm 0.01 \%$ (mean \pm standard error), nearly coincident with peak stress and the peak rate of acoustic emissions (i.e., cracking) (Renshaw and others, 2017). However, in sea ice deformed under confinement, such as during wave-induced bending and/or when ice is forced against a fixed obstacle such as a coastline or engineered structure, deformation might instead decrease ice permeability through the closure of both cracks and brine channels. Laboratory investigation of this process is difficult because typical spacing of brine drainage channels in natural sea ice can be several centimeters to several tens of centimeters (Freitag, 1999), necessitating the use of samples of dimensions up to a meter or more to capture a representative brine drainage channel network. For example, laboratory measurements of sea-ice permeability have been observed to be several orders of magnitude lower than permeabilities measured in the field (Freitag, 1999). The effect of a decrease of fracture permeability due to confining pressure is well known in rocks (Walsh, 1981).

Here we report the results of a first-of-its-kind large-scale field deformation experiment to investigate the impact of compressive loading on sea-ice permeability. Specifically, we performed a large-scale field indentation test while monitoring the permeability of the ice ahead of the indentor and 
observed spatially heterogeneous changes in permeability. We propose that the compression induced by the indentor is analogous to the compression induced by wave-induced bending or when ice is forced against a fixed obstacle. In our experiments, in some places, the permeability decreased by four orders of magnitude or more, while elsewhere, it increased by more than an order of magnitude. We analyze the stress field ahead of the indentor to predict the spatial distribution of deformation and show that the observed changes in permeability are consistent with expected changes in the mechanisms of deformation. To our knowledge, these are the first direct field observations of the impact of deformation on sea-ice permeability and suggest that deformation processes may need to be considered in analyzing how the increase in wave energy may affect both the coastal zones and the remaining ice pack.

\section{METHODS}

\subsection{The ice}

The field indentor experiment was performed on first-year sea ice formed in a protected cove within the Van Mijenfjorden fjord near Sveagruva in the Norwegian archipelago of Svalbard $(77.8829 \mathrm{~N}, 16.7755 \mathrm{E}$, Fig. 1). Water in the cove is hydraulically connected to the ocean via a narrow channel that permits tidal fluctuations of the water level in the cove yet protects the ice in the cove from wave action. At the time of testing in mid-March 2017, the ice was intermittently covered with up to several tens of centimeters of snow, which was removed within the test area prior to testing. Thin sections of the ice revealed columnar grain structure with $2-3 \mathrm{~cm}$ diameter vertical columns extending through the full thickness of the ice. The temperature gradient within the undeformed ice was nearly linear, ranging from $\sim-15$ to $-12{ }^{\circ} \mathrm{C}$ at the ice/air interface to $-2{ }^{\circ} \mathrm{C}$ at the bottom of the ice. Ice thickness within the test area was nearly uniform at $\sim 59 \mathrm{~cm}$, likely a result of the protective cove that may limit heterogeneity. Ice temperature approached $-5{ }^{\circ} \mathrm{C}$ at a depth of $50 \mathrm{~cm}$, which coincided with the percolation depth of the ice; boreholes drilled to shallower depths in undeformed ice remained dry while deeper boreholes filled with water.

\subsection{Indentation test}

In preparation for the field indentor experiment, a $1 \mathrm{~m} \times 2 \mathrm{~m}$ through-going (i.e., open at the top and bottom surfaces of the ice) rectangular hole was sawn into the ice into which the field indentor was lowered (Fig. 2). The field indentor consisted of two hydraulic rams attached to $60 \mathrm{~cm} \times 60 \mathrm{~cm}$ steel plates on either end. The hydraulic fluid pressure within the rams was manually adjusted to apply a $\sim 750$ $\pm \sim 50 \mathrm{kPa}$ horizontal compressive stress along the short dimensions of the rectangular hole. We conducted two separate indentor tests; during the first test, the force applied by each ram was approximately equal. While the second test was intended to replicate the first, during the second test, the force applied by the upper ram was, unintentionally, as much as $50 \%$ greater than that of the lower ram. The applied loading was held constant during the permeability testing described below. The maximum displacement rate of the rams was of the order $10^{-3} \mathrm{~m} \mathrm{~s}^{-1}$, which normalized by the ice thickness or size of the loading plate gives a characteristic strain rate of order $10^{-4} \mathrm{~s}^{-1}$ during the initial loading of the sample. This strain rate is of the same order of magnitude as the ductile-to-brittle transitional strain rate of saline ice at $-10{ }^{\circ} \mathrm{C}$ (Snyder and others, 2016). Although the mode of failure at this strain rate is macroscopically ductile, at least in laboratory-scale samples of both fresh (Renshaw and others, 2017) and saline ice (Snyder and others, 2016), inelastic deformation at this strain rate is partially accommodated by closure of brine pockets and drainage channels and, beginning at about one-quarter to onethird of the peak strength, by the initiation of non-propagating microcracks. After the stress was applied, a series of $10 \mathrm{~cm}$ diameter vertical boreholes were drilled into the ice in front of the indentor to $50 \mathrm{~cm}$ depth (Fig. 3). The depth of the borehole was controlled by drilling to a depth marked on the drill bit and varied within $\pm 1 \mathrm{~cm}$. The rate at which the holes filled with water was recorded using a Sea $\bullet$ Bird $^{\circledR}$

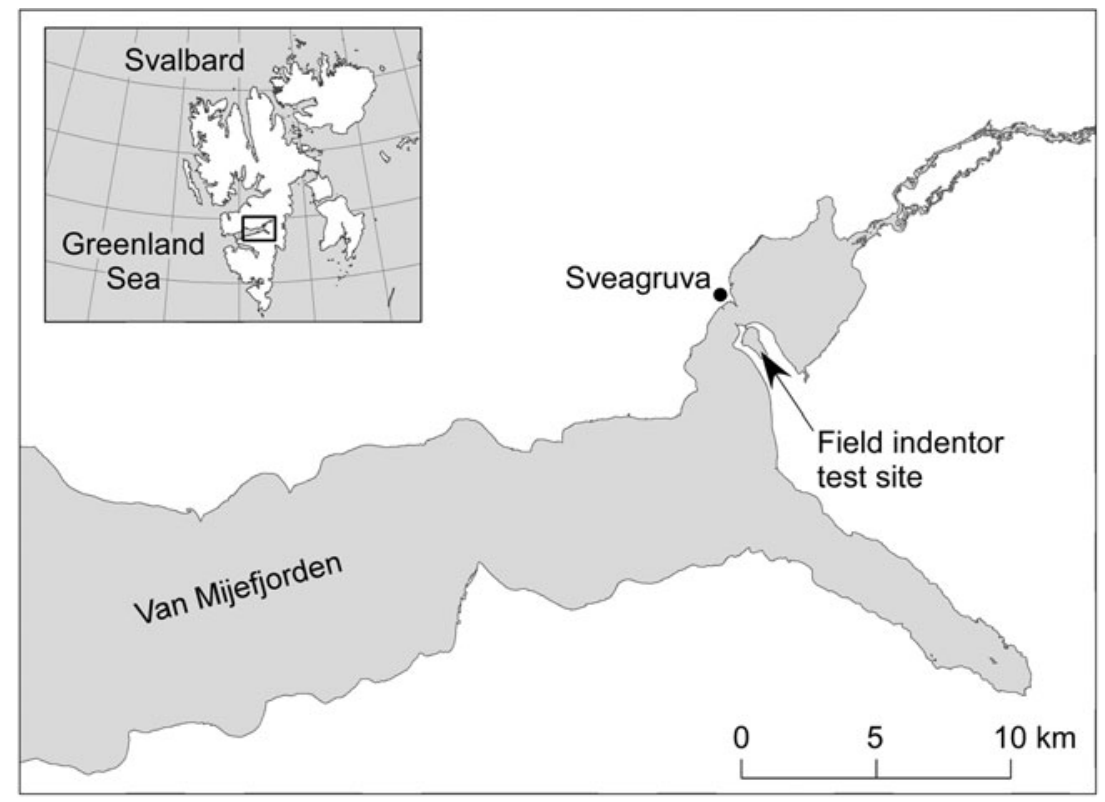

Fig. 1. Location of test site near Sveagruva in the Norwegian archipelago of Svalbard. 


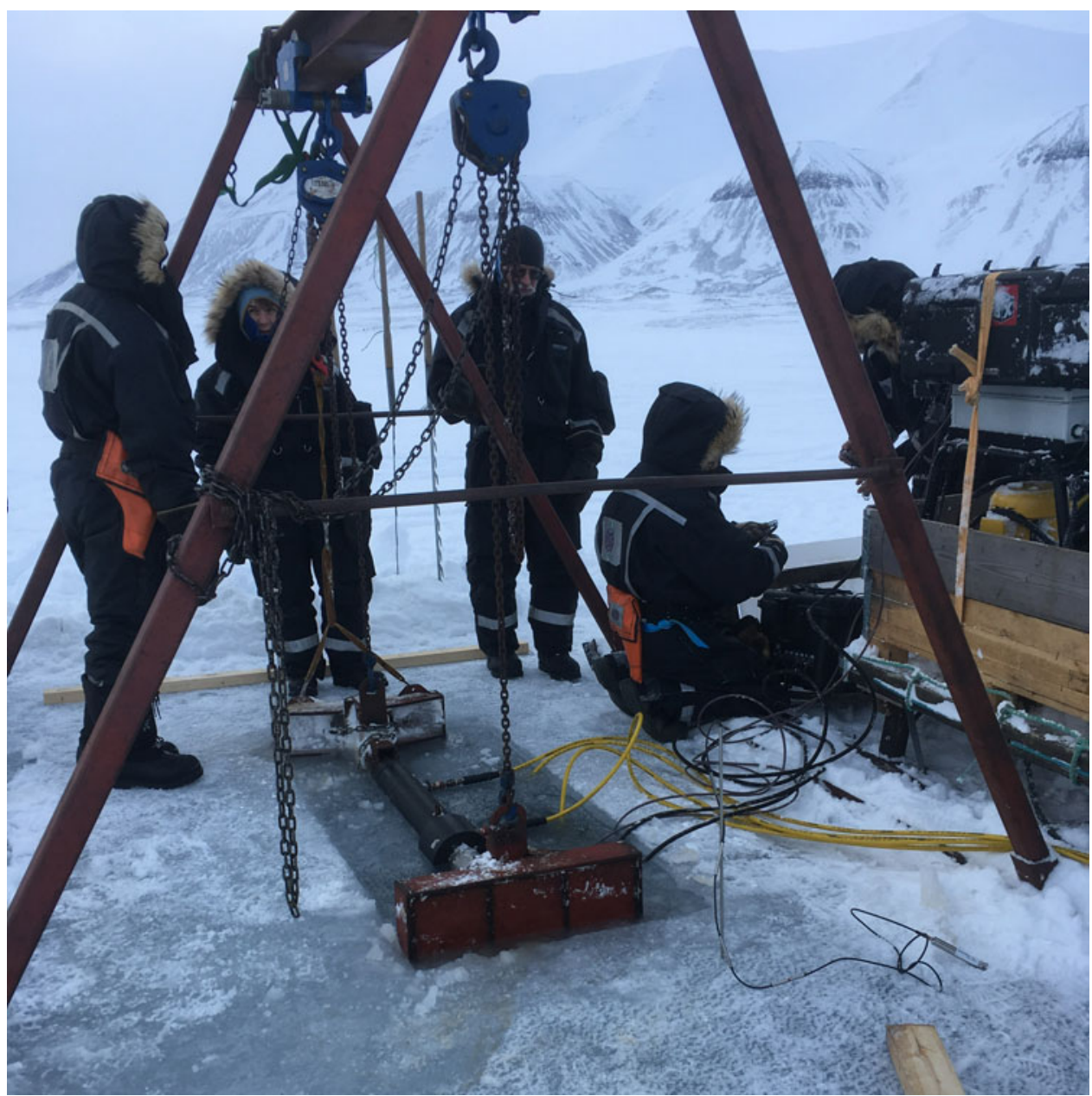

Fig. 2. Field scale indentor lowered into the rectangular hole cut into the ice.

pressure sensor. The rate of filling was used to estimate the permeability of the ice, as described below. To determine the undeformed permeability of the ice before the indentor was activated, separate $50 \mathrm{~cm}$ deep boreholes were drilled at locations at least several meters away from the indentor and then tested. To ensure that the permeabilities of these remote locations were unaffected by the activating/loading of the indentor, a new remote borehole was drilled and tested after the loading. Two separate indentation tests were performed on separate days in separate locations. The total duration of the first set of indentation and permeability tests was $\sim 20 \mathrm{~min}$, while the second set of tests was completed in $\sim 10 \mathrm{~min}$.

\subsection{Permeability test}

The filling of the drilled hole in ice with water is similar to a groundwater 'slug test' where observation of the rate of

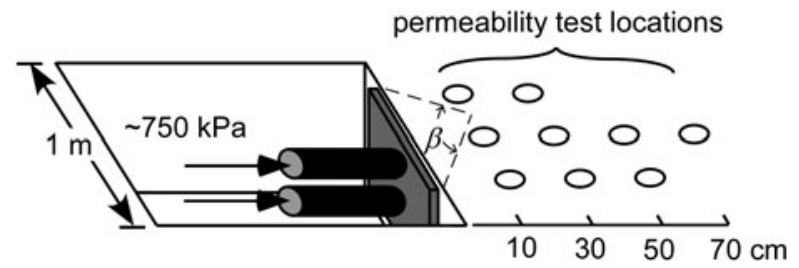

Fig. 3. Schematic of permeability borehole locations and coordinate system used in determining stress field. water-level change in a well is used to determine the permeability, $k$, near the well (Freitag, 1999; Eicken and others, 2002). Analyses of slug test data are generally based on analytical solutions for two- or three-dimensional flow to the well and are usually of the form

$$
k=F \frac{v}{\rho g t} \ln \left(\frac{h_{o}}{h}\right),
$$

where $v$ and $\rho$ are the fluid dynamic viscosity and density, respectively, $g$ is gravitational acceleration, $h$ is the hydraulic head, with $h=h_{O}$ at time $t=0$, and $F$ is a characteristic length shape factor that depends on the flow geometry (Hvorslev, 1951; Bouwer and Rice, 1976; Freitag, 1999). Here the hydraulic head is the difference in height between open water surface elevation and the borehole water level. Defining the dimensionless time and hydraulic head as

$$
h_{\mathrm{D}}=\frac{h}{h_{0}} \quad t_{\mathrm{D}}=\frac{k \rho g}{v L} t,
$$

where $L$ is the distance between the bottom of the borehole and the bottom of the ice pack, the expected change in hydraulic head in the borehole over time can be written as

$$
h_{\mathrm{D}}=\mathrm{e}^{-t_{\mathrm{D}}}
$$

Although the boreholes were not cased, water was observed to only enter from the bottom of the hole during the 
permeability tests; i.e., none was observed to enter from the sides. No water entered holes drilled to depths $<50 \mathrm{~cm}$. This is consistent with both the expected low permeability of the colder ice along the walls of the borehole and the strong anisotropy in the permeability of columnar ice, where, at least in laboratory-scale samples of fresh water ice, permeability along the columns is greater than across the columns (Renshaw and others, 2017). Laboratory measurements of the permeability of Arctic summer sea ice indicate that the along-column permeability, $k_{\mathrm{v}}$, is up to two orders of magnitude higher than the across-column permeability, $k_{\mathrm{h}}$ (Freitag, 1999).

The strong permeability anisotropy of columnar ice implies that flow below the borehole is likely nearly one dimensional in the vertical direction. In this case, the test is essentially equivalent to a falling head permeameter test (e.g., Fetter, 1988) where the shape factor $F=L / \gamma$, where $\gamma$ is a correction factor for lateral flow that depends on $L$ and on the permeability ratio $k_{\mathrm{h}} / k_{\mathrm{v}}$. Freitag (1999) determined $\gamma$ by numerically simulating slug tests in a transversely isotropic medium. For a length $L$ appropriate for our tests $(0.09 \mathrm{~m})$, Freitag (1999) estimated $\gamma=3$ for $k_{\mathrm{h}} / k_{\mathrm{v}}=1.0$ and $\gamma=1.1$ for $k_{\mathrm{h}} / k_{\mathrm{v}}=0.1$. That is, Eqn (1) slightly overestimates the vertical permeability due to lateral flow. However, in contrast to our observations of no fluid flow in the colder ice above the bottom of the borehole, the analysis of Freitag (1999) assumes the ice is permeable at depths above the bottom of the borehole. Figure 4 shows the results from a numerical analysis similar to that of Freitag (1999) except that in this case the ice is assumed impermeable above the bottom of the borehole (i.e., at depths $<50$ $\mathrm{cm})$. Lateral flow results in a more rapid filling of the borehole (more rapid decrease in hydraulic head) and thus an overestimation of vertical permeability by Eqn (1). For $k_{\mathrm{h}} / k_{\mathrm{v}}=1.0$, Eqn (1) overestimates $k_{v}$ by a factor of $\sim 5$, decreasing to a factor of $\sim 2$ for $k_{\mathrm{h}} / k_{\mathrm{v}}=0.1$ and to a factor of $\sim 1.2$ for $k_{\mathrm{h}} /$ $k_{\mathrm{v}}=0.01$. For $k_{\mathrm{h}} / k_{\mathrm{v}}<0.001, \gamma \sim 1$. Additional uncertainty in the estimated permeability arises from variations in the borehole depth, which directly affects $L$. The uncertainty in borehole depth $( \pm 1 \mathrm{~cm})$ corresponds to a $10 \%$ uncertainty in the estimated permeability. Thus, estimates of $k_{\mathrm{v}}$ using Eqn (1) are correct to within an order of magnitude or better for $k_{\mathrm{h}} / k_{\mathrm{v}} \leqslant 1.0$ for the observed variations in borehole depth. To the extent that the ratio $k_{\mathrm{h}} / k_{\mathrm{v}}$ is constant, the

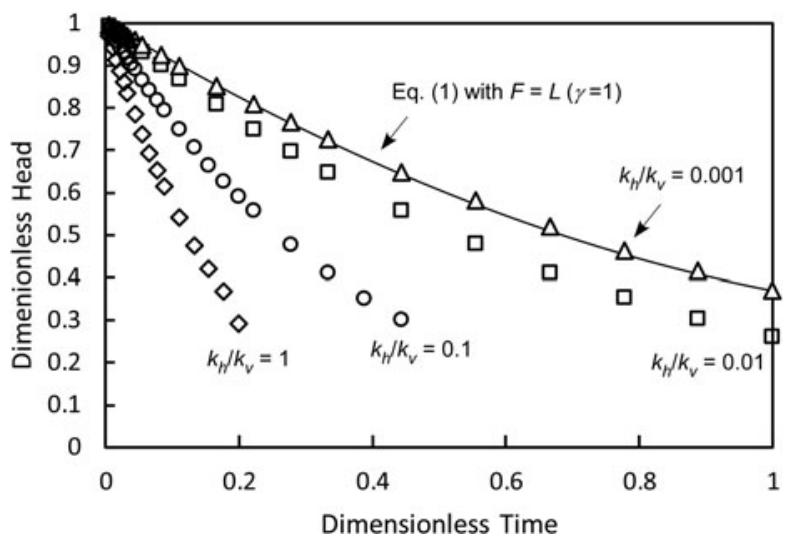

Fig. 4. Rate of decrease in hydraulic head versus time for a slug test with $\mathrm{L}=0.09 \mathrm{~m}$ and the indicated permeability ratio. For $k_{\mathrm{h}} / k_{\mathrm{v}}<$ 0.001 , the rate of decrease in hydraulic head is as predicted by Eqn (1) (solid line) with $F=L(\gamma=1)$.

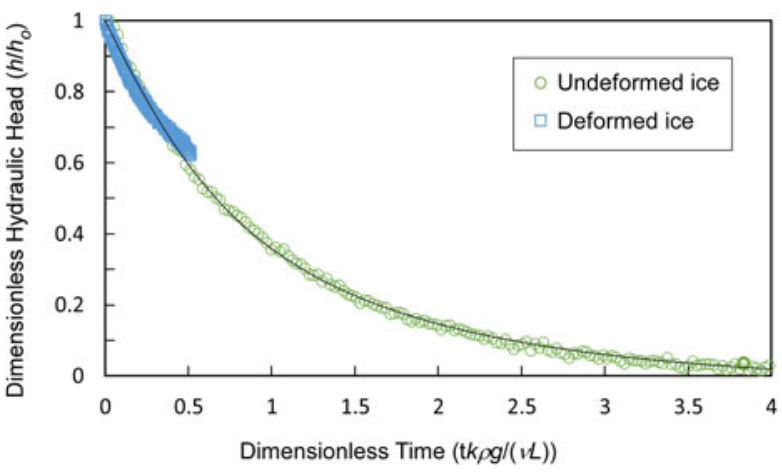

Fig. 5. Typical variation of hydraulic head in undeformed and deformed ice. Solid line is analytical solution (Eqn (3)).

relative difference in $k_{\mathrm{v}}$ between two boreholes as determined using Eqn (1) is accurate within $\sim 10 \%$.

\section{RESULTS}

Typical water level versus time results for the filling of a borehole in undeformed and deformed (i.e., remote from, and in front of, the indentor) ice are compared with the model solution (Eqn. 3) in Figure 5. Equally good matches between the model and observed changes in hydraulic heads occurred in all tests except those where either no water infiltrated into the borehole over $10 \mathrm{~min}$ or more, corresponding to a permeability $<10^{-10} \mathrm{~cm}^{2}$, or, in one case, where the borehole entirely filled in the $\sim 10 \mathrm{~s}$ required to remove the drill and place the pressure sensor, corresponding to a permeability $>10^{-5} \mathrm{~cm}^{2}$.

The permeability of undeformed ice was remarkably consistent within the test area, only varying between $1 \times 10^{-6}$ and $2 \times 10^{-6} \mathrm{~cm}^{2}$ in two tests in remote locations, one before the indentor was loaded and one after (Fig. 6). The permeability of the undeformed ice is likely more heterogeneous than reflected in these tests, yet less so than typically observed in undeformed sea ice because of the protected nature of the cove. In contrast, in the deformed ice ahead of the indentor, the permeability ranged over many orders of magnitude, to more than four orders of magnitude lower than that of undeformed ice (the detection limit of our methodology) in holes $10 \mathrm{~cm}$ from the indentor, to, in one test, more than an order of magnitude higher than undeformed ice (the maximum measureable permeability) $30 \mathrm{~cm}$ away from the indentor. This variation in permeability is far greater than the uncertainty in the slug test analysis due to the unknown permeability ratio $k_{\mathrm{h}} / k_{\mathrm{v}}$ and variations in

\begin{tabular}{|c|c|c|c|c|c|}
\hline $50 \mathrm{~cm}$ & $\begin{array}{c}<1 \times 10^{-10} \\
2 \times 10^{-6}\end{array}$ & $1 \times 10^{-7}$ & & & $1 \times 10^{-6}$ \\
\hline 30 & $\begin{array}{c}<1 \times 10^{-10} \\
6 \times 10^{-7}\end{array}$ & $3 \times 10^{-6}$ & $\begin{array}{c}2 \times 10^{-7} \\
>1 \times 10^{-5}\end{array}$ & $3 \times 10^{-6}$ & $2 \times 10^{-6}$ \\
\hline 10 & $\begin{array}{l}1 \times 10^{-8} \\
1 \times 10^{-7}\end{array}$ & $\begin{array}{l}1 \times 10^{-8} \\
2 \times 10^{-6}\end{array}$ & $5 \times 10^{-8}$ & & \\
\hline & 10 & 30 & 50 & $70 \mathrm{~cm}$ & Remote \\
\hline
\end{tabular}

Fig. 6. Permeabilities $\left(\mathrm{cm}^{2}\right)$ in front of $60 \mathrm{~cm}$ wide plate loading of $\sim 750 \mathrm{kPa}$. Font color indicates decrease (red) or increase (green) in permeability relative to undeformed ice (black). Multiple numbers in single table cell indicate results from two different tests. 
borehole depth. While reductions in permeability were generally greatest nearer the indentor, changes in permeability at a given location relative to the loading plate were not consistent across the two indentation tests, likely at least partially due to differences in the deformation field ahead of the indentor due to unequal loading of the plate by the two hydraulic rams during the second test. Nonetheless, the tests demonstrate that inelastic deformation can decrease sea-ice permeability by orders of magnitude in some locations and possibly increase permeability elsewhere.

\section{DISCUSSION}

Increased compressive stress in fresh or saline ice can impact permeability both by changing the ice temperature (Marchenko and Lishman, 2017) and by deformationinduced changes in the ice microstructure. In our field experiments, temperature changes of up to several degrees were measured in the upper $\sim 10 \mathrm{~cm}$ of ice with the onset of compression, but more muted changes (less than a degree) occurred at greater depths and likely only modestly impacted ice permeability there. Deformation impacts permeability via a variety of processes. Ice grain crushing and possibly recrystallization decrease grain size which, in porous granular materials, is correlated with a reduction in permeability (e.g., Shepherd, 1989). However, as the applied compressive stress of $\sim 0.75 \mathrm{MPa}$ is less than the compressive strength of the ice (see below), it is likely that any grain refinement ahead of the indentor was limited/negligible and thus this process is likely not a significant contributor to permeability changes in our experiments. Changes in the permeability ahead of the indentor were most likely due to either the opening of new cracks, thereby increasing the permeability, and/or the closure of cracks and the conversion of brine channels to brine pockets (Marchenko and Lishman, 2017), thereby decreasing the permeability. For example, if the ratio of brine channel diameter to spacing were 0.1 (e.g., $1 \mathrm{~cm}$ diameter channels spaced $10 \mathrm{~cm}$ apart), it would take $10^{3} \mathrm{~s}$ to close the brine channels at a strain rate of $10^{-4} \mathrm{~s}^{-1}$. This is similar to the duration of loading in our experiments.

The stress field induced by the indentor can be approximated by the solution for the stress in an elastic half space subject to a plate loading of pressure $P$ (e.g., Terzaghi, 1946)

$$
\sigma_{1}=\frac{P}{\pi}(\beta+\sin \beta) \quad \sigma_{3}=\frac{P}{\pi}(\beta-\sin \beta),
$$

where $\sigma_{1}$ and $\sigma_{3}$ are the highest and lowest principal stresses, respectively (compressive stress is taken as a positive quantity), and $\beta$ is the angle between two lines from the point of interest and either end of the plate (Fig. 3). Kim and others (2012) showed that within the highly confined region ahead of an indentor, microcracking associated with frictional sliding is suppressed and the dominant mode of deformation is ductile. Frictional sliding is suppressed where the confinement ratio $R=\sigma_{3} / \sigma_{1}$ exceeds a critical value $R_{\mathrm{c}}$, which depends on the coefficient of friction, $\mu$ (Schulson and Duval, 2009).

$$
R_{\mathrm{C}}=\frac{(1+\mu)^{1 / 2}-\mu}{(1+\mu)^{1 / 2}+\mu}
$$

The coefficient of friction of saline ice depends on both the temperature and sliding velocity (Schulson, 2015). For the conditions of the field indentation test (average temperature of $\sim-10^{\circ} \mathrm{C}$, sliding velocity of order $10^{-6} \mathrm{~ms}^{-1}$ where velocity was estimated from the product of grain size and strain rate), $\mu=0.5$ (Kennedy and others, 2000; Schulson and Fortt, 2012), the corresponding critical confinement ratio is $R_{\mathrm{c}}=0.38$. Using this critical value, the highly confined region ahead of the indentor where $R>R_{\mathrm{C}}$ is shown by the red shading in Figure 7 . Within this region, the permeability of the ice generally decreased, in many cases by orders of magnitude, likely indicating the closure of cracks and brine channels.

Marchenko and Cole (2017) found that when saline ice permeability is $>10^{-9} \mathrm{~cm}^{2}$, wave-energy dissipation is dominated by the migration of liquid brine through the ice. However, cyclic deformation of ice layers caused by waveinduced bending deformation induces compressive stresses within the ice. If the ice is confined and the compression sufficient (i.e., above some critical wave amplitude), the compressive stresses may decrease the permeability of the ice below $10^{-9} \mathrm{~cm}^{2}$ (such as occurred near the indentor), inhibiting brine migration and limiting wave-energy dissipation. Compression induced by smaller amplitude waves may not be sufficient to sufficiently decrease the permeability to inhibit brine migration. This suggests there may be a critical wave amplitude at which wave-energy dissipation by ice is significantly reduced; wave amplitudes above this critical value sufficiently decrease the permeability of the ice to inhibit brine migration, decreasing wave-energy dissipation.

Microcracking and attendant increases in permeabilty are expected to occur outside of the highly confined region if stress is sufficient for crack initiation. In laboratory studies of fresh and saline columnar ice at $-10{ }^{\circ} \mathrm{C}$, microcracking is inferred to initiate by the onset of acoustic emissions at a compressive stress of approximately one-quarter to onethird of the compressive strength, which for unconfined ice at $-5{ }^{\circ} \mathrm{C}$ is a few MPa (Schulson and Duval, 2009; Renshaw and others, 2017). For example, Renshaw and others (2017) observed the onset of acoustic emissions in

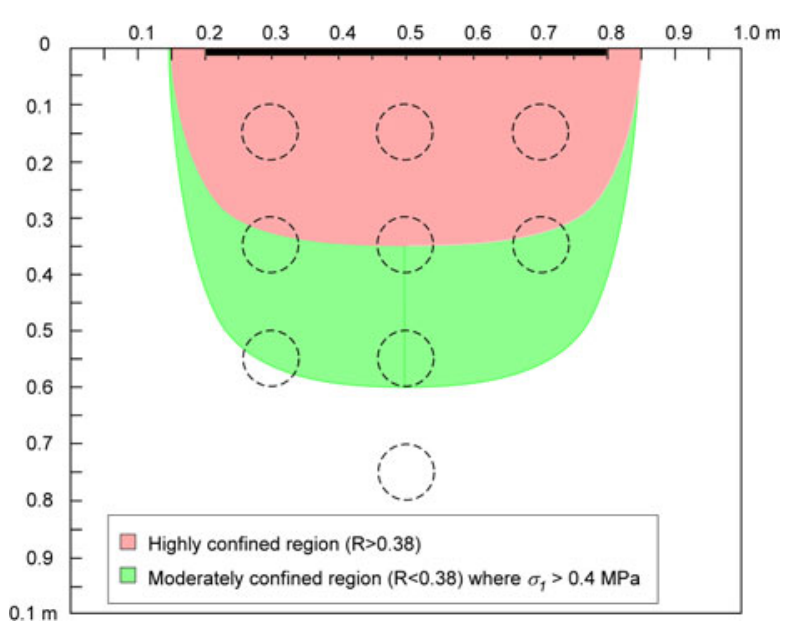

Fig. 7. Stress field in elastic half space subject to $60 \mathrm{~cm}$ wide plate (bold line) loading of $500 \mathrm{kPa}$. Crack closure and reduced permeability is expected in the shaded red region where the confinement $R>0.38$, sufficient to inhibit frictional sliding for coefficients of friction $\mu>0.5$. Microcracking and enhanced permeability is expected in the shaded green region where $R<$ 0.38 and $\sigma_{1}>0.4 \mathrm{MPa}$. The dashed circles indicate permeability borehole locations. 
laboratory-scale samples of fresh water ice compressed across the columns at a stress of 0.4 MPa. Using this as a representative value, the region where the confinement is sufficiently low for frictional sliding to occur $\left(R<R_{\mathrm{c}}\right)$ and where the stress is sufficiently high to initiate microcracking is shown by the green shaded region in Figure 7 . Increases in permeability generally occur within this region, although, with one notable exception, the increase in permeability is slight and perhaps not even significant given the expected heterogeneity of ice permeability.

Measured stresses in the sea-ice cover on the Arctic Ocean are generally a few tens up to about one hundred kPa (Richter-Menge and others, 2002; Tremblay and Hakakian, 2006) and wave-induced stresses in saline ice are generally a few hundred $\mathrm{kPa}$ or less for wavelengths $>100 \mathrm{~m}$ (Marchenko and Cole, 2017). These stresses are generally below that required to initiate microcracking in laboratory samples. This suggests that creep deformation is more likely to decrease ice permeability via the closure of both cracks and brine channels rather than to increase permeability via the initiation of new cracks. Within the high stress, high confinement region just ahead of the indentor, we observed decreases in permeability of several orders of magnitude (Fig. 6), with the decrease in permeability just ahead of the indentor sufficient for brine migration to no longer be the dominant mechanism of wave-energy dissipation (Marchenko and Cole, 2017).

Deformation-induced changes in permeability within natural ice pack may not be as dramatic due to differences in the level of stress, confinement and strain rate. Nonetheless, our results demonstrate that dramatic changes in permeability due to deformation are possible. Given the possible impact of permeability changes on critical sea-ice processes, including wave-energy dissipation, especially in late summer and early fall when the ice is warm and the fetch long, our results suggest that further work is warranted to more fully understand the impact of ice deformation on sea-ice permeability, particularly as increasing open water fetches generate larger waves, which may propagate farther into the pack ice and potentially break it up. The potential for ice break-up may be enhanced if the amplitude of the larger waves exceeds the critical amplitude, above which wave-energy dissipation associated with brine migration is significantly reduced.

\section{ACKNOWLEDGEMENT}

This work was partially supported by funding from the National Science Foundation (EAR - 1519706). Additional support for the fieldwork was provided by the Research Council of Norway (Sustainable Arctic Coastal and Marine Technology) and the Norwegian Centre for International Cooperation in Education (Safety of Industrial Development and Transportation Routes in the Arctic). All data from this work are available from the authors.

\section{REFERENCES}

Asplin MG, Galley R, Barber DG and Prinsenberg S (2012) Fracture of summer perennial sea ice by ocean swell as a result of Arctic storms. J. Geophys. Res. Oceans, 117, 1-12

Bouwer H and Rice RC (1976) Slug test for determining hydraulic conductivity of unconfined aquifers with completely or partially penetrating wells. Water Resour. Res., 12(3), 423-428
Collins CO, Rogers WE, Marchenko A and Babanin AV (2015) In situ measurements of an energetic wave event in the Arctic marginal ice zone. Geophys. Res. Lett., 42(6), 1863-1870.

Eicken H, Krouse HR, Kadko D and Perovich DK (2002) Tracer studies of pathways and rates of meltwater transport through Arctic summer sea ice. J. Geophys. Res. Oceans, 107(C10), 1-20

Fetter CW (1988) Applied hydrogeology. Merrill, Columbus.

Freitag J (1999) The hydraulic properties of Arctic sea ice - implications for the small-scale particle transport (in German). Ber. Polarforsch, 325, 1-150

Golden KM, Ackley SF and Lytle VI (1998) The percolation phase transition in sea ice. Science, 282(5397), 2238-2241

Golden KM and 5 others (2007) Thermal evolution of permeability and microstructure in sea ice. Geophys. Res. Lett., 34(16), 1-6

Hvorslev MJ (1951) Time lag and soil permeability in groundwater observations. US Army Corps of Engineers, Vicksburg, MS. Waterways Exp. Station Bull., 36, 1-50

Kennedy FE, Schulson EM and Jones DE (2000) The friction of ice on ice at low sliding velocities. Philos. Mag., 80(5), 1093-1110

Kim E, Golding N, Schulson EM, Løset S and Renshaw CE (2012) Mechanisms governing failure of ice beneath a sphericallyshaped indenter. Cold Reg. Sci. Technol., 78, 46-63

Kwok R (2001) Deformation of the Arctic Ocean sea ice cover: a qualitative survey. In Dempsey JP and Shen HH eds. Scaling laws in ice mechanics. Springer, New York, 315-322.

Marchenko A and Cole D (2017) Three physical mechanisms of wave energy dissipation in solid ice. Proceedings of the 24th International Conference on Port and Ocean Engineering under Arctic Conditions, Busan, Korea.

Marchenko A and Lishman B (2017) The influence of closed brine pockets and permeable brine channels on the thermo-elastic properties of saline ice. Philos. Trans. R. Soc. Math. Phys. Eng. Sci., 375(2086), 1-21

Marko JR and Thomson RE (1977) Rectilinear leads and internal motions in ice pack of western arctic ocean. J. Geophys. Res. Oceans Atmos. 82(6), 979-987

Pringle DJ, Miner JE, Eicken H and Golden KM (2009) Pore space percolation in sea ice single crystals. J. Geophys. Res. Oceans, 114, 1-14

Renshaw CE (1999) Connectivity of joint networks with power law length distributions. Water Resour. Res., 35(9), 2661-2670

Renshaw CE, Schulson EM and Sgward SJG (2017) Experimental observation of the onset of fracture percolation in columnar ice. Geophys. Res. Lett., 44(4), 1795-1802

Richter-Menge JA, McNutt SL, Overland JE and Kwok R (2002) Relating arctic pack ice stress and deformation under winter conditions. J. Geophys. Res. Oceans, 107(C10), 1-15

Schulson EM (2004) Compressive shear faults within arctic sea ice: fracture on scales large and small. J. Geophys. Res. Oceans, 109(C7), 1-23

Schulson EM (2015) Low-speed friction and brittle compressive failure of ice: fundamental processes in ice mechanics. Int. Mater. Rev., 60(8), 451-478

Schulson EM and Duval P (2009) Creep and fracture of ice. Cambridge University Press, Cambridge

Schulson EM and Fortt AL (2012) Friction of ice on ice. J. Geophys. Res. Solid Earth, 117, 1-18

Shepherd RG (1989) Correlations of permeability and grain-size. Ground Water, 27(5), 633-638

Snyder SA, Schulson EM and Renshaw CE (2016) Effects of prestrain on the ductile-to-brittle transition of ice. Acta Mater., 108, 110127

Stroeve JC and 5 others (2012) The Arctic's rapidly shrinking sea ice cover: a research synthesis. Clim. Change, 110(3-4), 10051027.

Terzaghi K (1946) Theoretical soil mechanics. John Wiley \& Sons, New York

Thomson J and Rogers WE (2014) Swell and sea in the emerging Arctic Ocean. Geophys. Res. Lett., 41(9), 3136-3140

Thomson J and 27 others (2016) Emerging trends in the sea state of the Beaufort and Chukchi seas. Ocean Model., 105, 1-12 
Tremblay LB and Hakakian M (2006) Estimating the sea ice compressive strength from satellite-derived sea ice drift and NCEP reanalysis data. J. Phys. Oceanogr., 36(11), 2165-2172
Walsh JB (1981) Effect of pore pressure and confining pressure on porosity and the transport properties of rock. Int. J. Rock Mech. Min. Sci. Geomech. Abstr., 18, 429-435

MS received 18 August 2017 and accepted in revised form 15 March 2018; first published online 7 May 2018 